ISSN-e: 2659 - 9589

\title{
Brais Pinto como autoaprendizaxe ${ }^{1}$
}

Nunca mellor definida a nosa vida común naquel grupo de madrigalegos dos últimos anos 50 e primeiros 60. Efectivamente, Brais Pinto como autoaprendizaxe. Brais Pinto como un colectivo de traballadores e estudantes galegos en Madrid que convivían para aprender, para formarse, para incidir na vida política e cultural e nada menos que para cambiar o mundo. Así pois, entre a realidade e a utopía. Era aquel, por tanto, un colectivo cunha praxe que viña a ser unha autoaprendizaxe permanente.

Hoxe, 50 anos despois, os braispintos sentimos a necesidade de rememorar aqueles tempos e de xuntarnos de novo. Xa a sentimos hai algún tempo. Por iso nos xuntamos de cando en cando. Témonos reunido con ocasión do 25 aniversario, do 30, do 40 e, hai poucos días, na Coruña, con ocasión do 50. Somos, uns para os outros, a mellor conciencia do paso do tempo. E, co paso dos anos, é como se gañara consistencia e cohesión aquel grupo noso que naceu case por azar. Pero que non por azar entrou en acción de distintas maneiras e con variados obxectivos.

¿Como nace, se forma e se constitúe ese grupo? ¿Como se vai poñer a funcionar? A xuntanza daqueles primeiros oito amigos (cinco traballadores: César Arias, Xosé Femández Ferreiro, Bautista Álvarez, Reimundo Patiño e Alexandre Cribeiro e tres estudantes: Xosé Luís Méndez Ferrín, Ramón Lorenzo e Bernardino Graña) ten lugar promediado 0 curso 1957-58 en Madrid, tal e como sinala Ana Acuña, a atentísima historiadora dos círculos literarios madrigalegos. Eu incorpórome un pouco máis tarde, no outono dese mesmo ano, cando eles se afanaban xa en empaquetar e enviar a toda Galicia a Bocarribeira de Otero Pedrayo, con quen fixeran unha foto moi de grupo e moi de inaugurar unha nova xeira co gran mestre de Trasalba...

En realidade, eu levaba xa tempo sabendo deles, da súa presenza no Centro Galego -naquel pequeno local da Praza de Oriente- onde eu ía diariamente calmar a sede da miña saudade (sen chegar a esa «metafísica da saudade» da que falaba Ramón Piñeiro e que tanto xenio lle dá a Ferrín, pero bastante entusiasmado, si, pola miña parte, coa obra de Rof Carballo Mito e realidade da Terra Nai, por exemplo). Mirábaos e reparaba neles. Trataba de escoitar as súas conversas. Xa coñecía do Instituto de Pontevedra a Cribeiro e a Ferrín. De Bernardino Graña oíralle eu falar ao meu amigo Carlos Baliñas...

Pero como resulta que eu son moi tímido, tardei un pouco en relacionarme con eles. Non sei se fun eu ou se foi algún deles quen falou primeiro. As ganas de facer algo que rompera aquela realidade grisallenta que nos envolvía fixo o resto. Ao pouco tempo xa

1 Este texto corresponde á intervención de Herminio Barreiro na conferencia que deu con motivo da Exposición «Brais Pinto. $O$ afiador revolucionario», o día 19 de abril do 2010 no Museo de Pontevedra. 
estaba eu con todos empaquetando o libro de Don Ramón e proporcionándolles novos subscritores e subscritoras dos libros de poesía deles mesmos xa programados para saír: Graña, Ferreiro, Lorenzo, Cribeiro (Poema do home que quixo vivir, A Noite, O que se foi perdendo, Acoitelado na espera).

¿Que era o que eu levaba a Brais Pinto? Unha tendencia política de esquerdas que era unha mestura da miña herencia familiar en clave de memoria republicana e dun certo autodidactismo comunista collido de aquí e de acolá, pero unha moi feble conciencia nacionalista. $O$ meu galeguismo reducíase daquela a unha ou dúas conferencias deslumbrantes de Otero Pedrayo, ao poema de Cabanillas na morte de Castelao, a algún libro mercado na librería de Luis Martínez e a certas referencias pontevedresas e de familias pontevedresas republicanas e galeguistas. Moi pouca cousa. A nivel persoal, pensando en Galicia como centro do noso mundo, Brais Pinto foi quen de axudarme a configurar con toda precisión a miña patria e foi formándome e conformándome, primeiro pouco a pouco e despois máis aceleradamente. Se non houbera coñecido os meus colegas do Brais, a miña vida tería sen dúbida discorrido por outros camiños. Pero diso só son consciente agora.

Brais Pinto era pois unha autoaprendizaxe permanente. Autoaprendizaxe que tiña lugar para todos e por parte de todos. Nun arco político-ideolóxico que podería ir dende o centro á esquerda e mesmo cunha certa despolitización nalgún caso. Por exemplo, Ferreiro. El mesmo fala diso nun libro que vai saír e do que xa me pasou un orixinal (De Xente Nova a Brais Pinto é o seu título provisional. É a historia de dous colectivos de mozos de Ourense e Madrid. Non esquezamos que Fernández Ferreiro é o inventor do nome Brais Pinto, un afiador de Nogueira de Ramuín — de onde el mesmo é- que deu a volta ó mundo cunha roda de afiar). Por outra parte, a Lorenzo e a César Arias tampouco os entusiasma a política.

En fin, as diferenzas, andando o tempo, faríanse máis fondas, pero só dende un punto de vista que poderiamos chamar táctico ou estratéxico, pero sempre cunha coincidencia grande nas cuestións de principios. ¿Que era o que nos unía? ¿Acaso non había tamén grupos dese estilo noutros sitios? Probablemente si. Pero en Brais Pinto falábase do feito diferencial galego en termos de Galicia nacionalidade ou de Galicia nación. Falábase de autodeterminación. Falábase dos textos de Lenin. Falábase de como coordinar os conceptos de cultura e política dentro dunha praxe política inconformista e transformadora. Nunha palabra: non se deixaba ir a cultura por un lado e a política por outro. Aquel colectivo era, polo menos, un colectivo antifranquista e antifascista. Cousa que se deixaría sentir en certas liortas que se viviron nos primeiros anos 60 .

Brais Pinto era iso. E se hoxe falamos de novo de todo iso e do que de innovación podía ter tal cousa naquel tempo é porque estamos a pensar, sobre todo, nos continuadores e no que veu despois. A historia, como dicía Pierre Vilar, é unha ciencia do futuro máis que do pasado. 0 pasado só interesa en tanto que comprensión duns feitos que explican 0 presente e configuran o futuro. Queremos saber do pasado para saber por onde tirar. Pero o que máis nos importa é o que vai vir. Esa é a nosa preocupación. Porque o pasado xa pasou. 
Así pois Brais Pinto actuará, sobre todo, no Madrid de 1959, 60, 61 e, xa un pouco menos -nesta súa primeira fase - no 62. Habería despois - tal e como pode verse na Exposición que aquí se ofrece- unha segunda fase nos últimos 60 e primeiros 70, impulsada por César Arias e Reimundo Patiño. Como di o Ferrín, tiñamos unha vida común bastante intensa. Sempre nos barrios do centro de Madrid. Sempre por San Bernardo, Pez, Puebla, Ballesta, Infantas, Carretas, Sol, Recoletos, Cibeles...

Faladoiros no Centro Galego e no Café dos Mariscos, visitas continuas ás tascas madrileñas, asistencia a Bibliotecas e Exposicións, tardes nos cines da Gran Vía, visitas á periferia tan degradada da gran metrópole (o Pozo do Tío Raimundo, unha badalada na conciencia), ceas na "Región Gallega» e convivencia dalgúns de nós en pensións diversas do Madrid da época. Todos xuntos nas sesións de traballo editorial dirixidas por César Arias (sempre mandando e co «látigo» disposto a asubiar no aire..., no vello Centro Galego e no que se ía inaugurar en Carretas). Ou parte do grupo facendo unhas e outras cousas... Unha vida común, como digo, pero tamén unha vida pública propia de cada un, unha vida privada e mesmo unha vida secreta e pensada en termos dunha certa clandestinidade. Non había alternativa.

¿Como era aquel Madrid que eu atopara xa no 55 na miña primeira visita á capital e que apenas cambiara agora, no outono do 58 , cando eu chegaba alí para estudar e para ficar nel por longo tempo? Era -téñoo dito outras veces - un Madrid pobre e mal vestido, coas feridas da guerra aínda á vista. Coa pegada das balas no Palacio de Oriente por exemplo. Pero tamén a cidade combativa na que aínda resoaba gloriosamente o eco duro e metálico da voz de Pasionaria nos seus mitins. Cando un andaba por Cuatro Caminos, por Atocha ou por Vallecas tiña a impresión de que percibía o ruído xordo dos motores da aviación fascista ametrallando o pobo. E cada día podiamos imaxinar, na Cidade Universitaria, a presenza dos sacos terreiros e os libros furados, parapetos insólitos do Madrid resistente na biblioteca da facultade de Filosofía e Letras. E pensabamos e imaxinabamos conversas de Neruda con Miguel Hernández na Casa de las Flores. Ou sentiamos un certo tremor e unha certa mágoa pola morte de Durruti alí preto.

Era aquel noso Madrid un Madrid dun ceo azul, esplendente e velazqueño, con aquel aire transparente tan famoso. Pero tamén un Madrid pintureiro, ruidoso e fascistizante que nos aturdía. Recordando cunha certa dor aqueles días, pensamos hoxe que, malia todo, por enriba da miseria suburbial e entre os caracois, as "cañitas" de cervexa, a auga impoluta do Lozoya e as patacas bravas, sempre atopabamos un oco para soñar.

Polo menos, na miña memoria sempre ficará aquel Madrid único e irrepetible. Gris ás veces. Ou azul. Tibio ou resplandecente, apaixonado ou deprimido, estrañamente calmo ou vertixinoso. Cidade das mil cores, con olor e sabor a multitude ou a patio de vecindade. Cidade que cingue, perfila e define as nosas lembranzas e que é capaz de absorbelas con voracidade. Cidade que deixa de ser "lugar» e se converte de súpeto en protagonista da nosa vida. Paisaxe tan humanizada que non parece unha paisaxe natural. Así era aquel Madrid pobre e celtíbero, pero sempre chulo e retrechero. 
¿Como funcionaba Brais Pinto?... De mil maneiras. O método non era o noso punto forte. Quen ordenaba, mandaba e dispuña o traballo editorial (jsempre a poesía na historia contemporánea de Galicia!) era César Arias, de San Clodio, un traballador cualificado de Dragados, un carácter forte, un gran corazón, un amante sempre enfervorizado da nosa terra. Era el a alma das relacións públicas do grupo. Sempre o foi. Era el o artífice principal á hora de crear infraestrutura. César, sempre tan dominante e asoballador, era o grande animador e impulsor do grupo. Un traballador en todos os sentidos da palabra. César Arias e Xosé Fernández Ferreiro son os decanos do grupo.

Despois do Poema do home que quixo vivir, jtan existencialista e tan de Saint-Germain-des-Près!, de Bernardino Graña, aparecería A Noite, de Fernández Ferreiro. 0 ulcismo era o concepto surrealista que empregaba Ferreiro para cualificar un certo tipo de poesía. Ferreiro, que traballaba en Suevia Films e adoraba o cine, dedicaríase despois, sobre todo, ao xornalismo -traballou moitos anos en La Voz de Galicia-, a viaxar e a escribir novelas. Agosto do 36 reflicte moi ben o moito que lle gustaban -e lle seguen a gustar- os westerns. Tanto nesa novela como en Tempo de centeo hai un serio compromiso político-moral por parte deste braispinto que se autopretende «apolítico» —como el nos recorda moitas veces.

Pero naqueles anos e na nosa tertulia "marisqueira», Ferreiro era un tipo ocorrente, moi amigo dos seus amigos, sempre con bromas co Patiño. E Patiño sempre de broma con el: «Ferreiro, este é o derradeiro reduto da cultura occidental», repetía sempre Reimundo cando viñamos de xantar da "Región Gallega» e pasabamos preto dunha igrexa protestante, á beira de San Bernardo. Repetíao tres veces. Era un ritual. E mesmo de fronte había unha tenda desas enxebres de Madrid na que se vendían linguas de vaca e sesos. En fin, unha "casquería». Pero que tiña un letreiro que dicía: «filología y trepanaciones». Chamoulle moitísimo a atención a Ferrín cando se enterou de semellante cousa.

Durante a comida - case sempre cea-, Ferreiro coidaba con mimo de que Patiño comese un pouco máis. Eu nunca vin ninguén tan lento no xeito de comer nin que comese tan pouco. Patiño enredaba e enredaba tempo e tempo diante dun prato de polbo con cachelos ou non daba acabado un anaco de lacón. Picaba co garfo e falaba, falaba e falaba. Comidas eternas aquelas, pero sempre cunha conversa marabillosa. Os dous eran clientes fixos daquela mestura de cociña galega e de bar madrileño que levaban Ramón e a súa nai.

Reimundo Patiño era un tipo excepcional. Foi un dos membros de Brais Pinto co que eu convivín máis. Andabamos xuntos moitas noites e tiñamos intensísimas conversas sobre a relación entre a política e as artes en xeral, en particular, entre a política e as artes plásticas. ¡Cantos cubatas temos bebido xuntos e canto temos falado sobre as relacións ideais que deberían existir nun Estado socialista entre a política e as artes!

A pintura foi sempre a súa dedicación absorbente e total. Eu nunca coñecín a ninguén que vivira tan intensamente a súa vocación. Para Patiño, traballar nun banco medio día era un tormento. Nunca lle chegaba a hora de marchar para o Kilombo (nome dun famoso estudio que tiña na rúa da llustración) a gravar, a debuxar e a pintar, mentres escoitaba música clásica, bebía tragos de viño peleón e fumaba tabaco negro. Resúltame aínda 
hoxe difícil imaxinar a alguén que domine a teoría da pintura como a dominaba el. Era un erudito de primeiro nivel en materia de pintura abstracta. $E$ tiña unha habilidade única para atopar novidades bibliográficas rigorosamente vangardistas no eido da literatura e das artes plásticas.

Ramón Lorenzo publicaría $O$ que se foi perdendo, poesía escura, atormentada, quizais un pouco damasiana. Porque Dámaso Alonso foi o seu profesor-titor, podiamos dicir, dende o primeiro momento. Foi el o que levou a Lorenzo polo camiño da investigación. Mantiveron unha relación estreita sempre. Ramón é hoxe unha autoridade no mundo da filoloxía. Todo un carácter, Ramón. Segue a ter os mesmos folgos que os que tiña naquel tempo. Ten moita poesía inédita gardada. Non hai quen lla faga publicar. Di que, como el é investigador, non pode mostrar o seu mundo poético, seguro que especialmente escuro, pechado, hermético - penso eu.

Bautista Álvarez sempre foi un pouco enigmático. Cun discurso moi armado e recorrente, era difícil discutir con el. Enormemente apaixonado, nunca daba o brazo a torcer. Pero, ao mesmo tempo, tiña habilidade para "a análise concreta da situación concreta", como diría Lenin. Foi sempre un nacionalista radical. Galicia sempre foi para el o substantivo. Moi estudoso, traballador e sistemático, puxo empeño en prepararse no eido da teoría política, pero, co paso do tempo, converteríase principalmente nun político moi pragmático, que non tardou en acadar a máis alta responsabilidade de dirección no Bloque Nacional Galego. Foi el, con Ferrín, Patiño, «Foz», Arxona, Queizán..., un dos fundadores da UPG. Brais Pinto está por tanto moi na historia do nacionalismo galego deste tempo noso.

Bernardino Graña era o noso poeta querido, agarimoso e un pouco consentido. Dinito, como lle chamaba o Críber, que, para a xente de Cangas, tampouco era Cribeiro, nin Alexandre, senón Pepiño, porque o seu nome completo era Xosé Alexandre. Graña andaba sempre ocupado e preocupado coidando a cohesión do grupo. Andaba sempre á procura de consensos. Era o gran conciliador. Hoxe mesmo teima por recuperar a memoria do noso grupo durante aqueles anos e anda a voltas agora mesmo co seu discurso de ingreso na Academia que xa dirixe o máis ilustre e ilustrado dos braispintos: Xosé Luís Méndez Ferrín. Dende un punto de vista eminentemente artístico e poético, Bernardino Graña quixo ser un innovador e un rompedor. E gustáballe sorprender. Aínda hoxe é así.

Alexandre Cribeiro era amigo e compañeiro dende os tempos remotos do Bacharelato no Instituto de Pontevedra. ¡Tempos marabillosos aqueles do Instituto, fronte á Alameda tan querida! E Cribeiro sempre con bromas e asustándonos a todos con todo tipo de trolas sobre os terribles exames e sobre os profesores. Soñar a vida con Cribeiro, camarada de tantas cousas. $O$ cine era a súa mirada permanente e a poesía o seu soño profundo. Acoitelado na espera era o seu primeiro libro de poemas. Cribeiro, dirixindo a TVE en Galicia. O gran acontecemento do retorno de Castelao, con Uxío Novoneyra no recitado e María Teresa Navaza na narración. E o Críber entregando o seu posto aos vermes... Tempos duros ían chegar. A señardade no puño. Xosé Alexandre Cribeiro. Amigos en Galicia e por Galicia. E amigos en Madrid e por Madrid. Compañeiros no Brais e camaradas de política 
partidaria. Irmáns en tantas cousas... Pero Alexandre, tamén, cheo de misterio e de silencio. O Alexandre dunha certa tristeza indefinible. Alexandre o noso.

E Ferrín. Con Ferrín xa en Pontevedra, nos primeiros 50, con gravata de lazo pola Alameda. Voce na néboa, un agoiro da nova galeguidade. ¡O galego, lingua literaria! ¡Si señor!..., como diría Ánxel Fole. Pronto aparecería Percival, un acontecemento. X. L. Méndez Ferrín. Así asinaba. Hai un bicho ao que lle chaman «non sei que méndezferrini». Unha vella afección que procede dos seus vellos relatos. Ou viceversa. ¿Será a pegada daquelas vitrinas con bichos de todas clases conservados en formol, que tiña Don Mariano, o profesor de Ciencias Naturais no Instituto de Pontevedra? Todo pode ser.

E Ferrín en Madrid (e a súa sombra en Compostela. Anos máis tarde: No ventre do silencio). Con Ferrín na Biblioteca Nacional. «Mañá teño un exame de Lingüística Románica e non sei nada", dicíame. Sentaba no butacón mentres eu desfiaba aquela Xeografía de Melón de Gordejuela, na que había que situar e saber todo o relativo ao cénit e o nadir da esfera celeste e as coordenadas con relación aos polos e ao ecuador celeste... Ao pouco tempo, achegábase Ferrín. «Non aguanto máis. ¿Vés ao cine?». E para alá iamos os dous...

Ferrín era o visionario de Brais Pinto. A síntese permanente de case todo. O intérprete da verdadeira historia de Galicia. Sempre recordarei un dos nosos paseos subindo do vello Centro Galego cara á Ópera e Santo Domingo. Con Bautista e con Patiño. Abordando a fondo a cuestión dos acontecementos de 1956 en Hungría. Ben, tan a fondo como podiamos (eu aínda lin hai ben pouco o formidable ensaio de Sartre sobre o tema...).

O Ferrín daqueles anos era a nosa mellor conexión Galicia/Europa. Xosé Luís amosábase normalmente bastante escéptico sobre todo o que poderiamos chamar "realismo crítico hispánico". Porque tamén el buscaba o seu mundo propio. E o seu mundo estaba lonxe da paisaxe celtibérica e moi no corazón da Europa das resistencias e das vangardas. El era, en fin, o guía intelectual daquel grupo.

Ferrín era, pois, a mellor conexión Galicia/Europa. E tamén a mellor conexión Galicia/ América. Conexións tendidas neste caso dende Madrid. Porque en Galicia había curtocircuítos do galeguismo establecido cos comunistas do exilio. Penso en particular en Luís Seoane, en Lorenzo Varela e en Luís Soto. Relacións con albricias e bombas artificiais son as que establecemos en Madrid con Luís Seoane e con Luís Soto. Abríasenos un mundo novo cheo de promesas. 0 mundo do mellor pasado para o mellor futuro. Un mundo republicano e de esquerdas fronte ao fascismo. Tiñamos que enlazar con ese pasado para atopar o vieiro xusto cara ao porvir.

Dentro desas posicións políticas mínimas e máximas, Brais Pinto era un grupo aberto. Ás actividades que algúns dos membros do Brais despregaron nos últimos anos 60 e primeiros 70 no mesmo Madrid, en Galicia e no estranxeiro, incorporaríase axiña Luís González Blasco «Foz», sempre preocupado pola batalla de ideas, e Camilo Suárez-Llanos, escritor e amigo daqueles anos. 
O grupo tería relacións sempre privilexiadas con Manuel María e con Xosé Manuel Beiras, figuras eminentes da historia galega contemporánea, que seguirían desenvolvéndose tempo despois con todos os membros do grupo, xa espallado un pouco por todas partes. E polos «Mariscos» irían tamén compañeiros e amigos de Ferreiro e Patiño (Mariano, Pla, Zamorano). Costa Clavell, amigo de todos, pero moi especialmente de Ferreiro, de Ferrín e de Patiño. Filgueira, xornalista no diario Ya. Requeixo, un lugués divertidísimo. Carlos de Mondoñedo, que non era de Mondoñedo senón de Riotorto.

No meu libro de "lembranzas escolares e universitarias» Recordar doe, recollo así a nosa conexión con Uxío Novoneyra... "Pero a "bomba" para Brais Pinto foi a presenza en Madrid de Uxío Novoneyra. Con el chegaba a caudalosa Galicia da que falara Neruda. Con el chegaban Os Eidos. Eu diría: con el chegou por fin a fusión da poesía, a literatura, a pintura e a política. E con el chegaron tamén os que el chamaba "os mozos de Pontevedra", a nova xeración xa máis politizada nuns casos e máis moderna e marchosa noutros: Luís Cochón, Daniel Pino, Manolo Portas. Coa presenza sénior de Manolo Domínguez, que preparaba a súa oposición (por certo, nun daqueles veráns, en Pontevedra, Manuel presentaríame a Xosé Fortes, vestido co seu uniforme das forzas armadas je facendo unha crítica radical do Réxime! Eu non sabía onde meterme...). E, pouco despois, Manuel Coia, o escultor, que acababa de triunfar en Vigo cunha exposición sorprendente. Uxío iría tamén polos Mariscos, con Carlos Oroza, que nos recitaba Se prohibe el paso, un poema incendiario que era unha auténtica declaración de guerra. Era coma un himno novo que soaba a todas horas nos Mariscos, no Café Gijón ou nas beirarrúas da Gran Vía. Unha arma cargada de futuro. Porque xa nada ía ser igual... Latexaba entre nós unha nova conciencia colectiva. Era o agoiro dos anos 60, do que sempre falou Uxío e que el mesmo rememora nos seus Soños teimosos"...

Remataban así aqueles anos de autoaprendizaxe en Brais Pinto...

Compostela, abril, 2010

(Publicado n’A Trabe de Ouro, núm. 86, 2011, páxs. 255-261.) 